Research Article

\title{
Effect of Video Assisted Teaching on Knowledge of BSc Nursing Students regarding Renal Dialysis for Chronic Renal Failure Patients
}

\author{
Abha Oriel', Linson CC $^{2}$ \\ ${ }^{1}$ RKDF College of Nursing, Bhopal, Madhya Pradesh, India. \\ ${ }^{2}$ Department of Nursing, Sarvapalli Radhakrishnana University, Bhopal, Madhya Pradesh, India \\ DOI: https://doi.org/10.24321/2348.2141.202101
}

I $\quad \begin{array}{lllll}\mathbf{N} & \mathbf{F} & \mathbf{O}\end{array}$

Corresponding Author:

Abha Oriel, RKDF College of Nursing, Bhopal, Madhya Pradesh, India.

E-mail Id:

abha.oriel@gmail.com

Orcid Id:

https://orcid.org/0000-0001-7797-3319

How to cite this article:

Oriel A, Linson CC. Effect of Video Assisted Teaching on Knowledge of BSC Nursing Students regarding Renal Dialysis for Chronic Renal Failure Patients. Trends Nurs Adm Edu2021;10(1):1-6.

Date of Submission: 2021-04-05

Date of Acceptance: 2021-05-28

\author{
$\begin{array}{lllllllllllll}\mathbf{A} & \mathbf{B} & \mathbf{S} & \mathbf{T} & \mathbf{R} & \mathbf{A} & \mathbf{C} & \mathbf{T}\end{array}$
}

Background: The present study was conducted to assess the effect of video assisted teaching on the knowledge gain of BSc Nursing students on renal dialysis for chronic renal failure patients.

Methods: An experimental design was chosen with pre test and post test of experimental and control group. The sample size was 60 registered BSc Nursing students divided into two groups - 30 in the experimental and 30 in the control group. The tools used for conducting the study included demographic variables, self structured questionnaire to assess knowledge of experimental and control group. The experimental group was given video- assisted teaching as an intervention and the control group was used for comparison only. The data were analysed with the help of descriptive and inferential statistics.

Result: The study clearly shows that there was a significant gain in knowledge of BSc Nursing students in experimental group with video assisted teaching which emphasises that renal dialysis for chronic renal failure patients is good for their health.

Conclusion: The BSc Nursing students can be benefited with video assisted teaching to improve knowledge and practice on renal dialysis for Chronic Renal Failure Patients and they can practice these interventions in clinical area in future.

Keywords: Renal Dialysis, Chronic Renal Failure Patients, Video Assisted Teaching

\section{Introduction}

Chronic Renal Failure (CRF) is a globally increasing condition that is most commonly treated with haemodialysis. It was historically termed as a term that encompasses all degrees of decreased renal function, from damaged-at risk through mild, moderate, and severe chronic kidney failure. ${ }^{1}$ End-
Stage Renal Disease (ESRD) is a total and permanent kidney failure. When the kidneys fail, the body retains fluid. Harmful wastes build up. A person with ESRD needs treatment to replace the work of the failed kidneys. ${ }^{2}$ Haemodialysis is now a standardized therapy and used as a life-sustaining therapy for more than 300,000 patients in the United States who have end-stage renal disease. It remained the most 
common treatment modality. ${ }^{3}$ Haemodialysis is the most common method used to treat advanced and permanent kidney failure. Since the 1760 s, when haemodialysis first became a practical treatment for kidney failure, we have learned much about how to make haemodialysis treatments more effective and minimize their side effects. ${ }^{4}$ Though we have improved procedures and types of equipment now, still haemodialysis remains to be a complicated process that needs a group effort from the complete health care team, including nephrologists, dialysis technicians and nurses, dieticians and social workers.

\section{Methods}

\section{Problem Statement}

Effect of video-assisted instructions on knowledge of BSc Nursing students on renal dialysis for chronic renal failure patients admitted at selected hospitals at Jabalpur, (M.P.).

\section{Objectives of the Study}

- Assess the knowledge score of BSc Nursing students in experimental group and control group on renal dialysis for chronic renal failure patients.

- Develop a video-assisted teaching (VAT) program on renal dialysis for chronic renal failure patients.

- Assess the effects of video-assisted teaching (VAT) on the experimental group regarding knowledge gain on renal dialysis for chronic renal failure patients.

- Compare the knowledge of experimental and control group regarding renal dialysis for chronic renal failure patients.

- Associate the pre-interventional level of knowledge of experimental and control group with their selected demographic variables.

\section{Null Hypothesis}

$\mathbf{H}_{\mathbf{1}}$ : There will be no significant difference in the knowledge score of the BSc Nursing students of the experimental group with video- assisted teaching on renal dialysis for chronic renal failure patients.

$\mathbf{H}_{2}$ : There will be no significant difference in the knowledge between control and experimental group after videoassisted teaching to experimental group on Renal dialysis for chronic renal failure patients.

$\mathbf{H}_{3}$ : There will be no significant association of the experimental and control group with their selected demographic variables on the gain of knowledge regarding renal dialysis for chronic renal failure patients.

\section{Research Methodology}

The research approach adopted in the study was evaluative research approach, to assess the effectiveness of videoassisted teaching to BSc Nursing students on renal dialysis for chronic renal failure patients.

\section{Study Design}

True experimental research design with pre-test and posttest of experimental and control group.

\section{Duration of Study}

6 weeks.

\section{Setting}

The study was conducted in selected college at Jabalpur, Madhya Pradesh.

\section{Criteria for Sample Selection}

\section{Inclusion Criterion}

- $\quad$ BSc Nursing students willing to participate in the study.

\section{Exclusion Criterion}

- $\quad$ BSc Nursing students writing supplementary exams.

\section{Plan for Data Analysis}

The plan for data analysis was as follows:

- Organisation of data and the information was conveyed in frequency and percentage.

- The knowledge on renal dialysis for chronic renal failure patients analysed in terms of frequency, percentage, mean and standard deviation.

- Unpaired t-test was used to test the significant difference in the knowledge between the experimental and the control group.

Ethical Clearance: Interview schedule was used to collect demographic and baseline data after receiving permission from the authority.

\section{Variables under Study}

- Independent Variable: The video-assisted teaching on renal dialysis for chronic renal failure patients

- Dependent Variable: Knowledge is a dependent variable that depends on video-assisted teaching

\section{Demographic Variables}

Age, religion, academic qualification and source of knowledge about renal dialysis for chronic renal failure patients.

\section{Sample}

The sample population consisted of 60 BSc Nursing students who fulfilled the inclusion criteria. Among them, 30 were taken in the experimental group and 30 were taken in the control group.

\section{Sampling}

In this study, a total of 60 BSc Nursing students were selected by simple random sampling technique.

\section{Development and Description of the Tool}

The following steps were taken for preparation of the tool: 
- Conducting an extensive review of literature from books, journals, manuals, reports and published researches, newspapers, and internet

- Consultation with experts

- Testing reliability and validity for correction and modification of the tools

Section A: Demographic variables.

Section B: Self-constructed questionnaire with thirty items to assess knowledge of BSc Nursing students on renal dialysis for chronic renal failure patients.

Section C: Preparation of video-assisted teaching on renal dialysis for chronic renal failure patients for intervention in the experimental group.

\section{Scoring Procedure}

Each question had 4 options from which the sample had to choose one correct answer. The right answer was scored as one and the wrong option was scored as zero. The scoring was interpreted as below:

- Inadequate knowledge - score less than $50 \%$

- Moderate knowledge - score between 51-75\%

- Adequate knowledge - more than $75 \%$

\section{Intervention}

A video-assisted teaching programme of 45 minutes duration was shown to BSc Nursing students of the experimental group.

\section{Method of Data Collection}

Informed written consent was taken from the samples and permission to conduct the study was obtained from the authorities.

The data was collected in the following phases:

Phase 1: A structured questionnaire consisting of 30 items was administered to BSc Nursing students of experimental and control group to assess the pre-test knowledge score on renal dialysis for chronic renal failure patients.

Phase 2: The video-assisted teaching session of 45 minutes was carried out for BSc Nursing students of the experimental group while the samples in the control group continued with the normal routine.

Phase 3: The same questionnaire was administered on the seventh day for both experimental and control group.

\section{Result}

\section{Demographic Data of the BSc Nursing Students}

It is observed from in Table 1, that in the experimental group a majority of BSc Nursing students 23 (76.66\%) belonged to the age group of $21-24$ years, 5 (16.66\%) were between 25 and 29 years and 2 (6.66\%) student were found in the age group of 30 years and above. In the control group, $22(73.33 \%)$ students belonged to $21-24$ years of age, 6 (16.66\%) students were between 25 and 29 years of age and $2(6.66 \%)$ students were found to be in the age group of 30 years and above.

Table I.Frequency and Percentage Distribution of Subjects as per Age, Religion, Professional Experience In Year, Educational Qualification, Socio-Economic Status, Source of Knowledge

$\mathrm{N}=60$ (Experimental -30 \& Control - 30)

\begin{tabular}{|c|c|c|c|c|c|}
\hline \multirow{3}{*}{ Characteristics } & \multirow{3}{*}{ Category } & \multicolumn{4}{|c|}{ Subjects Group } \\
\hline & & \multicolumn{2}{|c|}{ Experimental } & \multicolumn{2}{|c|}{ Control } \\
\hline & & $\mathbf{N}$ & $\%$ & $\mathbf{N}$ & $\%$ \\
\hline \multirow{3}{*}{ Age Group (years) } & $21-24$ & 23 & 76.66 & 22 & 73.33 \\
\hline & $25-29$ & 05 & 16.66 & 06 & 16.66 \\
\hline & $30 \&$ above & 02 & 6.66 & 02 & 6.66 \\
\hline \multirow{3}{*}{ Religion } & Hindu & 20 & 66.66 & 19 & 63.33 \\
\hline & Muslim & 03 & 10 & 06 & 20 \\
\hline & Christian & 07 & 23.33 & 05 & 16.66 \\
\hline \multirow{4}{*}{$\begin{array}{r}\text { Academic } \\
\text { Qualification }\end{array}$} & 12th standard & 24 & 80 & 25 & 83.33 \\
\hline & BSc completed & 01 & 3.33 & 00 & 00 \\
\hline & BSc not completed & 05 & 16.66 & 05 & 16.66 \\
\hline & Any other & 00 & 00 & 00 & 00 \\
\hline \multirow{3}{*}{ Source of Knowledge } & Newspapers \& magazines & 24 & 80 & 23 & 76.66 \\
\hline & Relatives & 03 & 10 & 05 & 16.66 \\
\hline & Any other & 03 & 10 & 02 & 6.66 \\
\hline
\end{tabular}


Among the total study subjects, a majority of the students 20 (66.66\%) were Hindus, 3 (10\%) students were Muslims and 7 (23.33\%) were Christians in the experimental group. In the control group, a majority of BSc Nursing students 19 (63.33\%) were Hindus, 6 (20\%) were Muslims and 5 (16.66\%) students were Christians.

A majority of participants 24 (80\%) had received education up to the 12 th standard, 1 (3.33\%) had completed BSc and $5(16.66 \%)$ could not complete graduation in the experimental group. In the control group, a majority of BSc Nursing students 25 (83.33\%) had received education up to the 12 th standard and $5(16.66 \%)$ could not complete graduation.

The source of knowledge for a majority of BSc Nursing students 24 (80\%) was newspapers and magazines, 3(10\%) gained knowledge from relatives and $3(10 \%)$ candidates gained knowledge from other sources in the experimental group. In the control group, the source of knowledge for a majority of BSc Nursing students 23 (76.66\%) was newspapers and magazines, $5(16.66 \%)$ gained knowledge from relatives and 2 (6.66\%) from other sources.

With regards to the experimental group - in pre-test - a majority of BSc Nursing students in pre-test that is 24 $(80 \%)$ had inadequate knowledge and $6(20 \%)$ of them had moderate knowledge but in post-test 4 (13.33\%) of them had moderate knowledge and $26(86.66 \%)$ had adequate knowledge.

With regards to the control group in pre-test a majority of BSc Nursing students 23 (76.66\%) had inadequate knowledge and 7 (23.33\%) had moderate knowledge. In post-test, 21 (70\%) of them had inadequate knowledge and 9 (30\%) had moderate knowledge.

Table 2.Frequency and Percentage Distribution of Overall Knowledge Score of Experimental and Control Group

\begin{tabular}{|c|c|c|c|c|c|c|c|c|c|}
\hline \multirow{4}{*}{ S. No. } & \multirow{4}{*}{ Level of Knowledge } & & & & & \multicolumn{4}{|c|}{$\mathrm{N}=60$ (Experimental - 30 \& Control - 30) } \\
\hline & & \multicolumn{4}{|c|}{ Experimental Group } & \multicolumn{4}{|c|}{ Control Group } \\
\hline & & \multicolumn{2}{|c|}{ Pre-test } & \multicolumn{2}{|c|}{ Post-test } & \multicolumn{2}{|c|}{ Pre-test } & \multicolumn{2}{|c|}{ Post-test } \\
\hline & & $f$ & $\%$ & f & $\%$ & $f$ & $\%$ & f & $\%$ \\
\hline 1. & Inadequate $(<50 \%)$ & 24 & 80 & - & - & 23 & 76.66 & 21 & 70 \\
\hline 2. & Moderate (51-75\%) & 6 & 20 & 4 & 13.33 & 7 & 23.33 & 9 & 30 \\
\hline 3. & Adequate (> 75\%) & - & - & 26 & 86.66 & - & - & - & - \\
\hline
\end{tabular}

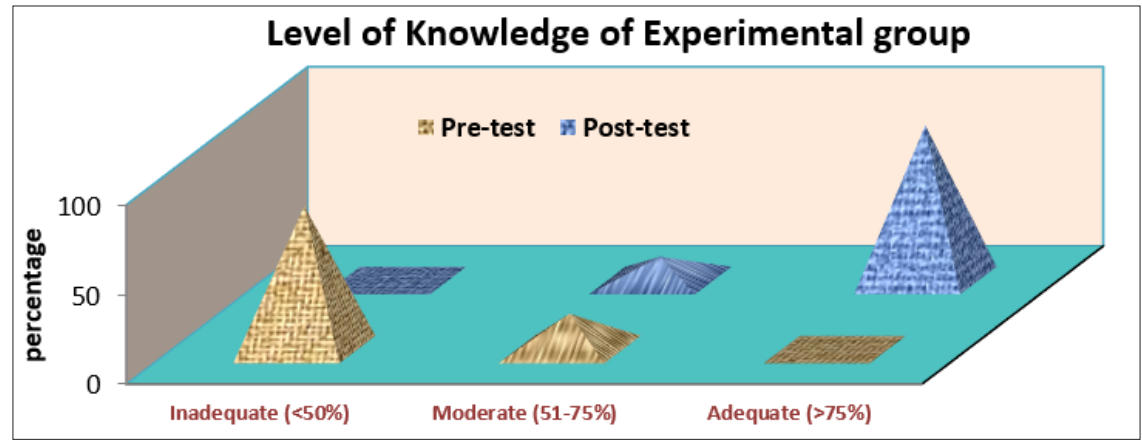

Figure I.Level of Knowledge of the Experimental Group

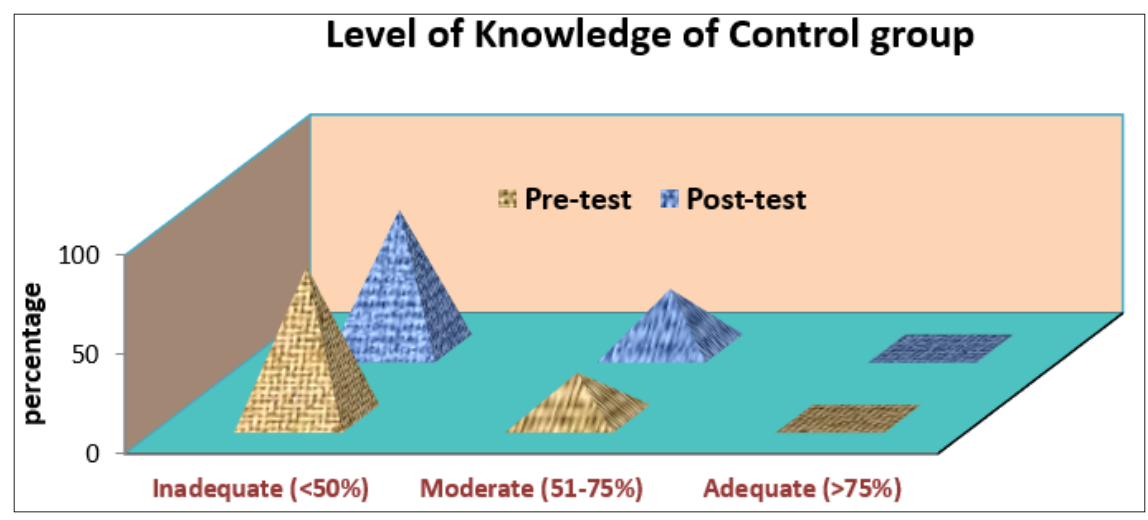

Figure 2. Level of Knowledge of the Control Group 


\section{Assessment of Knowledge Score}

\section{Association of Post-test Knowledge of Experimental and Control Group with Selected Demographic Variables}

The association of posttest knowledge of experimental and control group with their selected demographic variables was done using chi-square test. Out of many variables for the association, age, experience and the training institutes were found to be associated with knowledge. levels and at 29 degrees of freedom, implying that there is a substantial difference. In the pre-test of the control group, $76.66 \%$ of BSc Nursing students had inadequate knowledge and 23.33 per cent had moderate knowledge, while in the post-test of the control group, $70 \%$ of BSC Nursing students had inadequate knowledge and $30 \%$ had moderate knowledge.

\section{Conclusion}

The study showed an increase in the knowledge score of

Table 3.Comparison of Overall Pre-test and Post-test Mean, Standard Deviation, Mean Difference, and Paired -' $t$ ' value between Experimental and Control Group

\begin{tabular}{|c|c|c|c|c|c|c|c|}
\hline \multirow{2}{*}{ S. No. } & \multirow{2}{*}{ Group } & \multicolumn{2}{|c|}{ Mean } & Standard Deviation & Mean & \multirow{2}{*}{ Paired t -Test } \\
\cline { 3 - 8 } & & Pre-test & Post-test & Pre-test & Post-test & Difference & \\
\hline 1. & Experimental & 11.712 & 22.122 & 1.2332 & 1.6 & 10.41 & $1.2 \mathrm{df}-29$ \\
\hline 2. & Control & 11.714 & 12.721 & 1.4 & 1.3 & 1.007 & $0.46818 \mathrm{df}-29$ \\
\hline
\end{tabular}

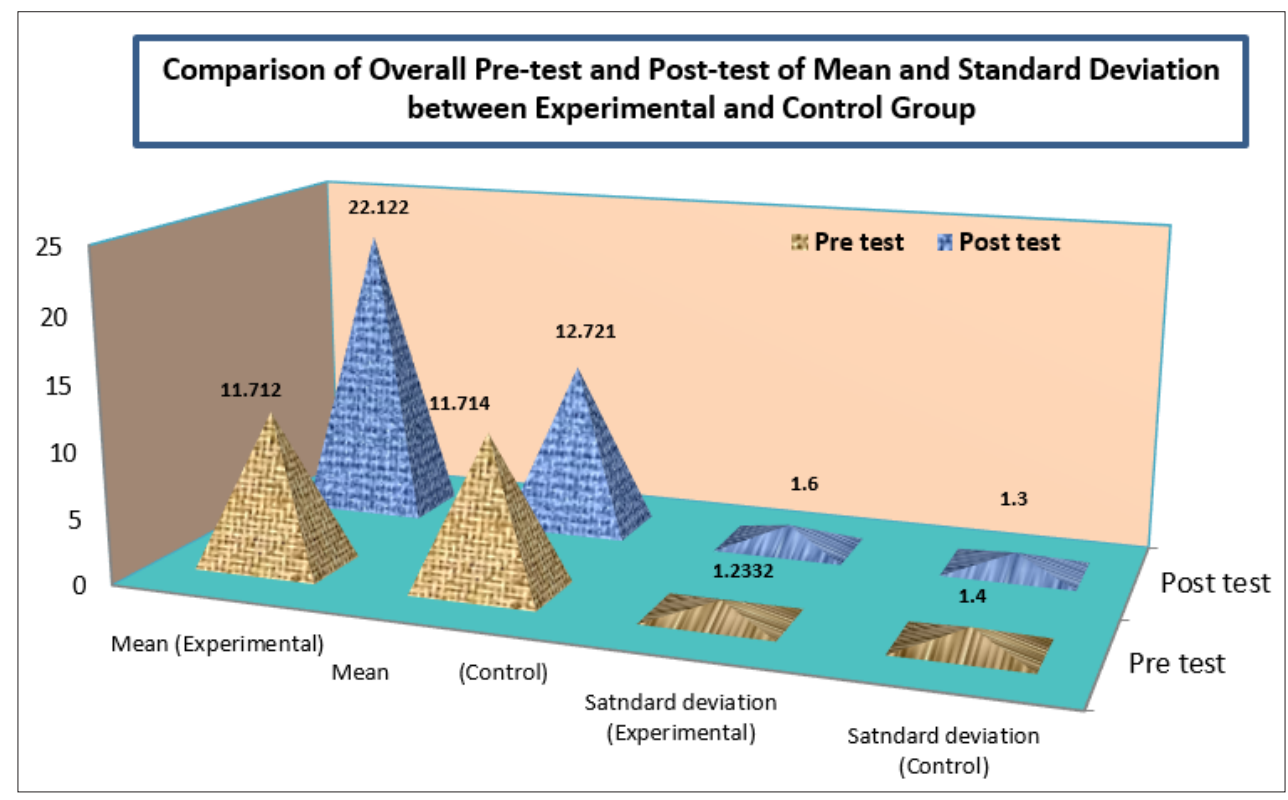

Figure 3.Comparison of Overall Pre-test and Post-test of Mean and Standard Deviation Between Experimental and Control Group

\section{Discussion}

As shown in Table 2, the assessment of knowledge in the experimental group in pre-test revealed that $80 \%$ of the BSc Nursing students had inadequate knowledge and $20 \%$ had moderate knowledge. The post-test knowledge score increased after video-assisted teaching to $13.33 \%$ having moderate knowledge, and $86.66 \%$ having adequate knowledge. As shown in Table 3 the post-test mean of the experimental group is 22.122 with a standard deviation of 1.6, whereas in the control group the post-test mean is 12.721 and the standard deviation is 1.3. The value obtained is 1.2. The null hypothesis is dismissed since the Calculated Value (CV) is greater than the Table Value (TV) at the 0.005 the experimental group after video-assisted teaching on the subject. Hence we should include video-assisted teaching to promote knowledge on the subject among BSc Nursing students to render good care to the patient admitted with chronic renal failure for renal dialysis.

\section{Recommendation and Nursing Implication}

- The study can be done with larger samples for better generalisation.

- Similar studies can be conducted in other settings also.

\section{Nursing Administration}

The nurse administrator should organize in-service education and training programmes on renal dialysis for 
chronic renal failure patients. It will improve the knowledge of BSc Nursing students.

\section{Confidentiality of Data}

The feedback forms obtained from BSc Nursing students are kept confidential. Only the principal investigator has the access to these documents.

\section{Source of Funding: Self}

\section{Conflict of Interest: None}

\section{References}

1. Ramspek $C L$, Nacak $H$, van Diepen $M$, van Buren $M$, Krediet RT, Rotmans JI, Dekker FW, the NECOSAD Study Group. Pre-dialysis decline of measured glomerular filtration rate but not serum creatinine-based estimated glomerular filtration rate is a risk factor for mortality on dialysis. Nephrology Dialysis Transplantation. 2017;32(1):89-96. [Google Scholar]

2. Burkhalter F, Sannon H, Mayr M, Dickenmann M, Ernst S. Prevalence and risk factors for chronic kidney disease in a rural region of Haiti. Swiss Med Wkly. 2014;144:w14067. [PubMed] [Google Scholar]

3. Deif HIA, Elsawi K, Selim M, NasrAllah MM. Effect of an educational program on adherence to therapeutic regimen among chronic kidney disease stage5 (CKD5) patients under maintenance hemodialysis. Journal of Education and Practice. 2015;6(5):21-33. [Google Scholar]

4. Mushi L, Marschall P, Fleßa S. The cost of dialysis in low and middle-income countries: A systematic review. BMC Health Services Research. 2015;15(1):506. [Google Scholar] 